\title{
RESEÑAS
}

\section{Yáñez, Juan Carlos. (Coord.). Gobernar es alimentar. Discursos, legislación y políticas de alimentación popular. Chile, 1900-1950.}

Valparaíso: América en Movimiento, 2018, 160 pp.

El objetivo de este libro es aportar al estudio de un periodo clave en la formulación e implementación de políticas públicas sobre la alimentación en Chile (p. 11). En ese sentido, todos sus artículos consideran tres temas fundamentales: la «cuestión social» (p. 40) chilena entendida como la emergencia de problemas urbanos a consecuencia de la industrialización en determinadas zonas del país a inicios del siglo XX; el proceso de «medicalización de la sociedad» (p. 91) en donde los médicos asumieron la «cuestión social» (p. 91) como una responsabilidad propia; y el Estado, que es abordado como un actor clave en la identificación e implementación de soluciones a la «cuestión social» ( $\mathrm{p}$. 12). Asimismo, salvo el primero, los artículos se refieren a políticas públicas en sus distintas etapas: formulación, debate e implementación. Incluso, los dos últimos textos se refieren a productos resultantes de ellas. Además, cada artículo explora aspectos poco abordados por la historia de la alimentación.

El primer artículo, «Alimentación y nutrición en Chile, Siglo XX. Una mirada historiográfica», fue escrito por el editor del libro. $\mathrm{Su}$ objetivo es establecer el estado del conocimiento de la historia de la alimentación en Chile, para debatir los alcances de investigación del tema (p. 17). El autor presenta referencias para distintos fenómenos, pero cuestiona la falta de conexión de estos trabajos con los debates médicos y su poca profundización en las dinámicas sociales (pp. 20-23). Cabe precisar que no se trata de un ensayo historiográfico, pues solo se limita a mencionar fenómenos, temas y áreas de trabajo, mas no ensaya una explicación del porqué surgieron estas investigaciones o perspectivas.

El segundo artículo, también escrito por Yáñez, se titula «El Primer Congreso de Alimentación Popular (Valparaíso, 1931). Debates y Propuestas». Su objetivo central es explorar la necesidad de vinculación política de la comunidad médica en su esfuerzo por participar en la formulación de políticas públicas sobre la alimentación (p. 39). El autor aborda este tema en el contexto de la «cuestión social» chilena, describiendo brevemente los esfuerzos realizados por los médicos para organizarse gremialmente desde mediados del siglo XIX ( $p$. 45). Esto los constituyó en un grupo de interés que buscaba alianzas políticas en pro de la intervención social (p. 40). En este sentido, este trabajo aborda a dicho congreso como manifestación de un deseo expreso de los médicos por discutir sobre la alimentación pública y las medidas necesarias para afrontarla (p. 48).

Aunque el artículo es interesante por su propuesta, cabe mencionar que el trabajo se limita a ser descriptivo. Evidencia de ello es que el espacio dedicado al Congreso de Alimentación Popular es de tan solo cuatro páginas (de 14), donde dos de ellas son un listado de las conclusiones a las que llegó el congreso, mientras

(C) Los autores. Este artículo es publicado por ISHRA, Revista del Instituto Seminario de Historia Rural Andina de la Facultad de Ciencias Sociales de la Universidad Nacional Mayor de San Marcos. Este es un artículo de acceso abierto, distribuido bajo los términos de la licencia Creative Commons Atribución 4.0 Internacional (CC BY 4.0) [https://creativecommons.org/licenses/by/4.0/deed.es] que permite el uso, distribución y reproducción en cualquier medio, siempre que la obra original sea debidamente citada de su fuente original. 
que las demás se refieren estrictamente a las características del congreso (pp. 47-48).

El tercer artículo, «Alimentación y eugenesia. Aproximaciones desde Chile: 19001950», fue escrito por Marcelo Sánchez. Aquí se aborda el debate entre intelectuales sobre la alimentación como un tema de política pública. El texto se refiere, como puntos fundamentales, a la importancia de este tema en las demandas obreras de inicios del siglo XX (p. 57) y al establecimiento de la caloría como unidad estándar de medida del gasto energético, el cual fue adoptado rápidamente por intelectuales vinculados al Estado chileno como Francisco Puelma Tupper y Eduardo Cruz Coke (pp. 58-61).

En este texto, el autor aborda las perspectivas católicas sobre la eugenesia, las cuales solicitaban el compromiso del Estado en procurar el abastecimiento de alimentos a las familias chilenas, y fueron críticas del liberalismo económico por dejar el tema alimentario a merced de las leyes de libertad y competencia (p. 6466). El capítulo también aborda la perspectiva laica, que está más preocupada por el balance energético entre trabajo y alimentación orientado a la formación de trabajadores sanos ( $\mathrm{pp}$. 73-74), siendo este el punto mejor abordado del texto.

El cuarto artículo, "“La Leche fortalece y dignifica. La leche es sangre blanca que rejuvenece". El problema de la leche y la Ley de Pasteurización Obligatoria (1930-1935)», fue escrito por Xaviera Salgado como parte de su tesis de maestría. Este texto tiene por objetivo «caracterizar y analizar el debate sobre la pasteurización obligatoria en Chile» (p. 84), ubicándose en las etapas de formulación y debate de la política pública. Uno de los argumentos del trabajo es que la pasteurización fue una preocupación central en el debate médico ( $\mathrm{p}$. 85), ello debido a que se consideraba a la leche como un producto proteínico por excelencia. Sin embargo, su mala higiene y altos costos hicieron que su promoción por parte del Estado fuera problemática (pp. 84-88). En ese sentido, el autor rescata la importancia del debate sobre la Ley de Pasteurización Obligatoria, la cual tuvo como precedente las presiones sociales que en 1924 lograron regular cuatro aspectos de la producción lechera en Santiago de Chile: constitución, producción, distribución y venta, y fiscalización (p. 95).

El siguiente artículo, también escrito por Yáñez, se titula «La encuesta Dragoni-Burnet sobre alimentación popular (1935)». En él se analiza la encuesta de nutrición realizada por representantes de la Sociedad de las Naciones en 1935, a raíz del convenio de cooperación firmado con Chile. En ese sentido, este trabajo se ubicaría en las etapas de formulación e implementación de la política pública. Esta encuesta resulta importante pues fue utilizada en el debate político-social de la época, además de ser referencia en varios trabajos historiográficos. Sin embargo, la encuesta aun no ha tenido un análisis directo (p. 103).

Cabe destacar que el trabajo inserta a la encuesta dentro del impacto económico-social que tuvo la Gran Depresión en Chile, pues esta generó la necesidad de que el Estado intentara conocer a fondo la situación de la población chilena a través de estudios, monografías y encuestas sobre las condiciones de vida de las familias obreras (pp. 105-108). Asimismo, el autor ofrece un análisis breve y conciso de la lógica de la encuesta, sus preceptos metodológicos, su aplicabilidad, sus unidades de análisis, sus dificultades de aplicabilidad y algunos resultados que ofreció (pp. 114-126).

El último artículo se titula «Cartilla de Alimentación en el Embarazo Normal: Guía para el buen comer de las madres por la buena nutrición de los hijos. Chile, 1947» y fue escrito por Claudia Deichler. El texto se enfoca en la etapa de formulación e implementación de la cartilla al interior de la Caja del Seguro Obrero (CSO) como parte de su interés en la alimentación de las mujeres embarazadas en su rol como cabezas de familia (p. 134). Destacamos del texto su definición de la cartilla «como un tratado breve y elemental de un oficio o arte» 
(p. 137) que se emplea para difundir algún aspecto determinado del saber durante campañas públicas. Es decir, le reconoce un rol de divulgación del conocimiento, de guía técnica para los profesionales y de un sentido moralizador de las conductas, diseñados con la intención de reglamentar los cuerpos a fin de establecer un orden social con determinados hábitos alimenticios (pp. 137-139).

Varios de los artículos del libro ofrecen adiciones de contenido dentro de sus conclusiones, que quizás no pudieron incorporar en otras secciones del texto. Por ejemplo, Yáñez agrega al final de su texto que una de las conclusiones del CAP se debió a que el tema de la alimentación se había transformado en objeto de política internacional (p. 52); o que la encuesta Dragoni-Burnet no se limitó a diagnosticar, sino que también se propuso acciones para revertir la situación (p. 130). Sánchez incorpora tardíamente que el debate parlamentario sobre la ley de pasteurización se desarrolló en dos polos opuestos: los niños morían por la leche de mala calidad o morían por no consumirla (p. 101). Aunque estos son datos importantes, deberían ser incorporados durante el desarrollo del texto y no como una conclusión que se obtiene del mismo.

Por otro lado, rescatamos que el libro ubique a la familia como unidad mínima de análisis en varios de los textos, aunque sin una mayor profundización. Creemos que la familia es un sujeto histórico que merece mayor atención, siendo el tema de la alimentación un fenómeno clave para poder hacerlo. Este es un aspecto que los tres últimos textos del libro cumplen con explorar.

Finalmente, desde una mirada de la historia de las políticas públicas, este libro supone un aporte al proveer estudios de caso sobre su formulación, discusión e implementación. Aunque no hay una teorización o profundización de lo que implica una política pública, a partir de la lectura de los textos se puede entender a este concepto como la acción del Estado para resolver un problema social. Para ello, presentan varios casos históricos sobre un problema en particular.

\section{Carlos Luis Paredes Hernández}

https://orcid.org/0000-0002-6662-9720

carlos.paredes@unmsm.edu.pe

Universidad Nacional Mayor de San Marcos

Publicado online: 10/08/2021 